\title{
ARTICLE
}

\section{Surgical results and factors affecting outcome in adult patients with sensory exotropia}

\author{
Eun Hye Jung $\mathbb{B}^{1,2} \cdot$ Seong-Joon $\mathrm{Kim}^{2,3}$
}

Received: 24 November 2017 / Revised: 15 May 2018 / Accepted: 27 July 2018 / Published online: 28 August 2018

(c) The Royal College of Ophthalmologists 2018

\begin{abstract}
Purpose To report the results of surgical treatment for sensory exotropia and to examine the factors associated with the surgical outcome.

Methods The records of patients with sensory exotropia who were older than 18 years at the time of surgery and were followed up for at least 1 year postoperatively were retrospectively reviewed. Patients with visual acuity of $\leq 20 / 100$ in the amblyopic eye were enrolled. Surgical success was defined as a final deviation of $<10$ prism diopters (PD) at distance in the primary position. Preoperative patient characteristics, surgical procedures performed, and early postoperative ocular alignment were evaluated as potential factors associated with the surgical outcome.

Results A total of 64 patients were included, of whom 40 (62.5\%) achieved surgical success, four (6.3\%) showed overcorrection, and 20 (31.3\%) experienced recurrence over an average follow-up duration of $2.0 \pm 1.2$ years. Preoperative distant and near angles of deviation were significant factors associated with surgical outcome. Regardless of the high rate of recurrence, initial postoperative large overcorrection did not guarantee a positive result. Instead, presence of initial postoperative esodrift was related to surgical success. Multivariable analysis revealed that only the preoperative distant angle of deviation was significantly associated with surgical outcome.

Conclusion The long-term outcome of surgery for sensory exotropia was satisfactory, and patients with small preoperative distant angle of exodeviation showed more favorable outcome.
\end{abstract}

\section{Introduction}

Sensory strabismus is generally defined as secondary deviation resulting from unilateral vision loss caused by anisometropic amblyopia or organic pathologies, such as optic nerve or retinal abnormalities, corneal opacity, and cataract $[1,2]$. Sensory strabismus surgery should not be solely regarded as an esthetic operation, and the functional

Seong-Joon Kim

ophjun@snu.ac.kr

1 Department of Ophthalmology, Chuncheon Sacred Heart Hospital, Chuncheon, Korea

2 Department of Ophthalmology, Seoul National University College of Medicine, Seoul, Korea

3 Department of Ophthalmology, Seoul National University Hospital, Seoul, Korea improvements that can be obtained should not be underestimated [3].

Few studies have examined the surgical outcome for secondary strabismus, and in those studies, $50.0-90.6 \%$ of patients met the authors' definition of successful outcome, which somewhat varied across studies. Additionally, the inclusion criteria in most studies were not uniform and heterogeneous groups were included, such as patients with sensory exotropia and esotropia, primary and secondary strabismus, and children and adults [4-6].

The factors reported to affect the surgical results after intermittent exotropia surgery vary widely, including age at the time of surgery, preoperative angle of deviation, refractive errors, type of surgery, and early postoperative ocular alignment [7]. However, little is known regarding the factors associated with surgical outcome in sensory exotropia [4, 8-10].

This study investigated the surgical results for sensory exotropia in adults and examined the factors associated with surgical outcome. 
Table 1 Surgical dosage used for sensory exotropia in this study

\begin{tabular}{lll}
\hline $\begin{array}{l}\text { Prism } \\
\text { diopters }\end{array}$ & $\begin{array}{l}\text { Lateral rectus recession/ } \\
\text { medial rectus resection } \\
(\mathrm{mm})\end{array}$ & $\begin{array}{l}\text { Unilateral lateral rectus } \\
\text { recession }(\mathrm{mm})\end{array}$ \\
\hline 15 & & 8.5 \\
20 & $5 / 5$ & 9.5 \\
25 & $6 / 4$ & \\
30 & $6 / 5$ & \\
35 & $7 / 5$ & \\
40 & $8 / 5$ & \\
45 & $8 / 6$ & \\
50 & $9 / 6$ & \\
55 & $10 / 6.5$ & \\
60 & $10 / 8$ & \\
70 & $11 / 8$ & \\
$80-103$ & $12 / 8-10$ & \\
\hline
\end{tabular}

\section{Methods}

The Institutional Review Board of the Seoul National University Hospital approved this study. The medical records of patients who underwent surgery for sensory exotropia at more than 18 years of age at Seoul National University Hospital between September 1, 2003 and October 31, 2015 were reviewed retrospectively.

Patients were included with unilateral vision loss caused by anisometropic amblyopia or organic congenital or acquired disorders such as optic nerve or retinal abnormalities, corneal opacity, and cataract. Patients with vertical deviation, dissociated vertical deviation, or oblique muscle overaction were also included. Exclusion criteria were as follows: intermittent, paralytic, or restrictive strabismus (e.g., surgical repair of retinal detachment via buckle, glaucoma via drainage device, or blow out fracture); corrected visual acuity $\geq 20 / 100$ in the amblyopic eye; history of strabismus surgery; and extraocular muscle injury via trauma. In addition, patients who received retrobulbar anesthesia during retinal surgery and those who were followed up for less than 12 months were excluded.

\section{Preoperative ophthalmic examination}

All patients underwent complete ophthalmological examinations before surgery, and the following data were recorded: sex, age at the time of surgery, preoperative best-corrected visual acuity with all refractions performed under cycloplegia, distant and near angle of deviation, and associated strabismus (dissociated vertical deviation, oblique muscle dysfunction, vertical deviation). Distant and near deviation was measured at $6 \mathrm{~m}$ and $33 \mathrm{~cm}$, respectively, using the Krismky test if the ocular fixation was poor or using alternate prism and cover test if the visual acuity was adequate, with appropriate spectacle correction when required.

\section{Surgical technique and postoperative assessment}

All surgeries were performed under general anesthesia by a single surgeon (S-JK) based on the largest angle of preoperative deviation measured at distance or near. Table 1 provides the formula that was used for the surgical procedures according to the surgeon's experience. Patients underwent unilateral recession of the lateral rectus muscle and resection of the medial rectus muscle of the amblyopic eye. Patients with exotropia of $<25$ prism diopters (PD) both at distance and near underwent unilateral lateral rectus recession. Before 2009 , adjustable sutures were used with the "bow tie" technique, with suture adjustments performed within the first $24 \mathrm{~h}$ after surgery, as needed. From 2009 to 2014, adjustable sutures were used with the "short tag noose technique," with adjustments performed within 5 days after surgery as required [11]. The general goal of the adjustment was an initial overcorrection of $<10$ PD. Postoperative assessments were performed at 1 day, 1 week, and 3, 6, and 12 months after surgery, with annual follow-up thereafter. Postoperative measurements of deviation were performed in the same manner as the preoperative measurements. Patients were divided into one of the following surgical outcome groups based on the distant angle of deviation at the last postoperative visit: success, overcorrection, or recurrence. Surgical success was defined as esodeviation or exodeviation of $<10$ PD or as orthotropia at distance. Overcorrection was defined as esodeviation of $\geq 10 \mathrm{PD}$, and recurrence was defined as exodeviation of $\geq 10$ PD. Both overcorrection and recurrence were considered to signify surgical failure.

On the basis of early postoperative distant deviation at day 1, patients were assigned to three groups: (1) esodeviation of $\geq 10 \mathrm{PD}$; (2) esodeviation/orthotropia of 0-10 PD; (3) exodeviation of 1-10 PD

\section{Statistical analysis}

All statistical analyses were performed with the Statistical Package for Social Sciences version 23.0 for Windows (SPSS Inc, Chicago, IL). A $P$ value of $<0.05$ was considered to be significant. The Pearson chi-squared test and the Mann-Whitney test were used to compare patient characteristics and surgical outcomes. Linear-by-linear association was performed to compare the surgical outcomes between the early postoperative alignment groups. The Kruskal-Wallis test was used to compare the postoperative angles of deviation between the early postoperative alignment groups. Multivariable logistic regression analysis that included factors determined to be statistically significant by univariate analysis was performed. 
Table 2 Demographics and ocular characteristics of patients and factors affecting surgical results

\begin{tabular}{|c|c|c|c|c|}
\hline & $\begin{array}{l}\text { Success } \\
(n=40)\end{array}$ & $\begin{array}{l}\text { Recurrence } \\
(n=20)\end{array}$ & $\begin{array}{l}\text { Overcorrection } \\
(n=4)\end{array}$ & $P$ value \\
\hline Age at surgery for exotropia, years & $\begin{array}{l}34.9 \pm 15.2 \\
(18 \text { to } 71)\end{array}$ & $\begin{array}{l}31.3 \pm 13.4 \\
(18 \text { to } 59)\end{array}$ & $47.0 \pm 5.5(42$ to 54$)$ & $0.397^{\mathrm{a}}$ \\
\hline $\operatorname{Sex}(M: F)$ & $20: 20$ & $12: 8$ & $3: 1$ & $0.464^{\mathrm{b}}$ \\
\hline \multicolumn{5}{|l|}{ Preoperative deviation, PD } \\
\hline Distance & $\begin{array}{l}40.3 \pm 15.8 \\
(15 \text { to } 78)\end{array}$ & $\begin{array}{l}51.4 \pm 17.6 \\
(28 \text { to } 103)\end{array}$ & $36.3 \pm 8.5(25$ to 45$)$ & $0.013^{\mathrm{a}}$ \\
\hline Near & $\begin{array}{l}36.6 \pm 13.2 \\
(15 \text { to } 71)\end{array}$ & $\begin{array}{l}46.5 \pm 17.5 \\
(15 \text { to } 103)\end{array}$ & $36.3 \pm 8.5(25$ to 45$)$ & $0.012^{\mathrm{a}}$ \\
\hline Distance-Near & $\begin{array}{l}3.7 \pm 6.9 \\
(-5 \text { to } 28)\end{array}$ & $5.8 \pm 7.2(0$ to 21$)$ & 0 & $0.222^{\mathrm{a}}$ \\
\hline Visual acuity of the affected eye & & & & $1.000^{\mathrm{b}}$ \\
\hline $20 / 200-20 / 100$ & 12 & 6 & 0 & \\
\hline$<20 / 200$ & 28 & 14 & 4 & \\
\hline \multicolumn{5}{|l|}{ Refractive errors, D } \\
\hline Fellow eye & $-2.0 \pm 3.3$ & $-1.4 \pm 3.3$ & $-1.3 \pm 2.7$ & $0.965^{\mathrm{a}}$ \\
\hline Affected eye & $-2.1 \pm 4.5$ & $-0.8 \pm 2.0$ & $-2.0 \pm 5.2$ & $0.717^{\mathrm{a}}$ \\
\hline Causes of vision loss & & & & $0.156^{\mathrm{b}}$ \\
\hline Congenital disorder & 5 & 7 & 0 & \\
\hline Anisometropia & 5 & 1 & 1 & \\
\hline Other acquired disorder & 30 & 12 & 3 & \\
\hline $\begin{array}{l}\text { Surgery for disease-causing vision } \\
\text { loss }\end{array}$ & 21 & 13 & 2 & $0.357^{\mathrm{b}}$ \\
\hline Associated strabismus & 21 & 11 & 4 & $0.855^{\mathrm{b}}$ \\
\hline $\begin{array}{l}\text { Combined surgery for associated } \\
\text { vertical strabismus }\end{array}$ & 15 & 6 & 3 & $0.566^{\mathrm{b}}$ \\
\hline Adjustable suture & 29 & 13 & 4 & $0.550^{\mathrm{b}}$ \\
\hline Postoperative adjustment & 11 & 3 & 0 & $0.172^{\mathrm{b}}$ \\
\hline Postoperative follow-up, years & $\begin{array}{l}1.9 \pm 1.1(1.0 \text { to } \\
5.3)\end{array}$ & $\begin{array}{l}2.4 \pm 1.6(1.0 \text { to } \\
6.6)\end{array}$ & $1.2 \pm 0.4(1.0$ to 1.8$)$ & $0.147^{\mathrm{a}}$ \\
\hline
\end{tabular}

$P$ values were tested between groups of success and recurrence

Data are presented as mean \pm standard deviation

$D$ diopters, $P D$ prism diopters

${ }^{a}$ Mann-Whitney test

${ }^{\mathrm{b}}$ Pearson $\chi^{2}$ test

\section{Results}

Sixty-four patients met the inclusion criteria. The mean age of the patients was $34.5 \pm 14.5$ years (range, 18-71 years). The mean preoperative distant exodeviation was $43.5 \pm 16.8$ PD (range, 15-103) and near exodeviation was $39.5 \pm 14.9$ PD (range, 15-103). At 1 year after surgery, 41 patients $(64.1 \%)$ achieved surgical success, five patients (7.8\%) showed overcorrection, and 18 patients $(28.1 \%)$ experienced recurrence. At the last follow-up (mean, range: 2.0, $1.0-6.6$ years), 40 patients $(62.5 \%)$ achieved surgical success, $4(6.3 \%)$ showed overcorrection, and 20 (31.3\%) experienced recurrence. If surgical success was defined based on the near angle of deviation, 39 patients $(60.9 \%)$ achieved surgical success, $8 \quad(12.5 \%)$ showed overcorrection, and $17(26.6 \%)$ experienced recurrence at last follow-up. No patient underwent repeat surgery during the follow-up period.

Table 2 summarizes the patient demographics. Of the preoperative variables investigated (sex, age at surgery, best-corrected visual acuity, refraction, distant and near angle of deviation, difference of distant and near angle of deviation, and associated strabismus), the distant and near angles of deviation were found to be significantly associated with surgical success $(p=0.039,0.023$, respectively). Except in the overcorrection group with a small number of cases, the distant and near angles of deviation were also significantly larger in the recurrence group than in the success group $(p=0.013,0.012$, respectively). Figure 1 shows the distribution of the 


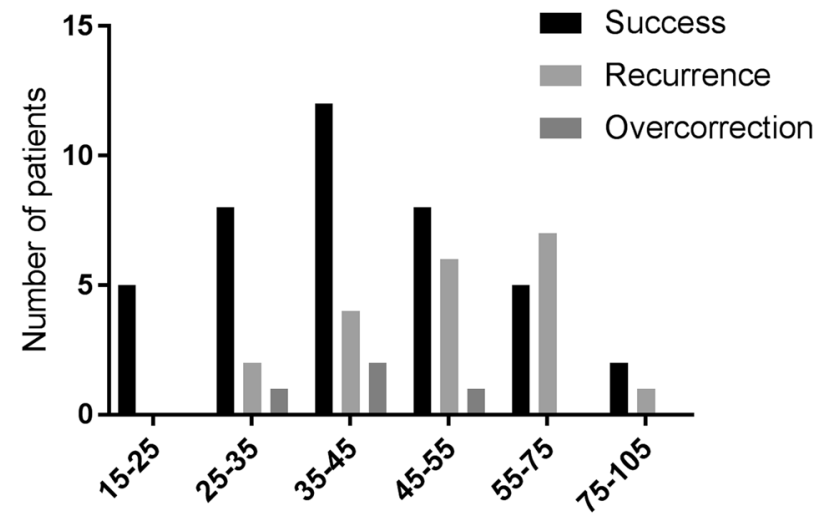

Preoperative angle of deviation (PD)

Fig. 1 Distribution of preoperative angle of deviation of patients according to surgical results. The preoperative distant angles of deviation were larger in the recurrence group than in the success group

preoperative distant angle of deviation of patients according to surgical results.

To evaluate the effect of visual acuity on postoperative success, patients were grouped according to the visual acuity of the amblyopic eye on the basis of 20/200. There was no significant difference in surgical success among the different visual acuity groups $(p=0.156)$.

In reality, there were some difficulties in evaluating age at onset of vision loss in a definitive manner due to retrospective review. Instead of evaluating age at onset of vision loss, disease duration was evaluated as a factor influencing surgical outcome, and we classified the causes of vision loss in the operated eye as follows: congenital disease (e.g., persistent hyperplastic primary vitreous, congenital cataract, congenital ptosis, or congenital corneal opacity), anisometropic amblyopia, and other acquired diseases (e.g., retinal diseases such as retinal detachment or chorioretinitis, optic neuropathy, glaucoma, traumatic cataract, corneal laceration, or intraocular foreign body). Both causes of vision loss and surgery for disease-causing vision loss were not significantly related to surgical success.

Of the 64 patients, $46(72 \%)$ received adjustable sutures, and 14 underwent postoperative adjustment. Among these 14 patients, postoperative adjustment was performed within the first $24 \mathrm{~h}$ after surgery in 13 patients and 2 days after surgery in one patient. There was no significant difference in the use of adjustable sutures, postoperative adjustment, and combined surgery for associated vertical strabismus between the success and failure groups.

\section{Early postoperative alignment}

Table 3 provides the deviations at postoperative day 1 . At day 1, successful outcome was highest in patients with a postoperative alignment of $0-10 \mathrm{PD}$ of esodeviation/ orthotropia. However, there was no significant trend between early postoperative alignment and surgical outcome $(p=0.370)$. Although the surgical results showed a relatively high rate of recurrence, large overcorrection did not improve surgical results. Additionally, of the seven patients in the esodeviation group with postoperative alignment of $>10$ PD, four patients showed surgical recurrence at the final follow-up.

The mean angles of deviation at each postoperative time point in the three groups, divided on the basis of postoperative deviation at day 1 , are shown in Table 4. Most of the patients had postoperative exodrift after surgery. However, 14 patients $(21.9 \%)$ showed esodrift during the first postoperative week; the mean angle of the esodrift was $-5.6 \pm 3.4 \mathrm{PD}$ (range, -13 to -2 ), and the presence of postoperative esodrift was related to surgical success $(p=0.042)$. Of these 14 patients, one was in the esodeviation group with postoperative alignment of $>10 \mathrm{PD}$, ten were in postoperative alignment group of $0-10$ PD of esodeviation/orthotropia, and three were in the exodeviation group with postoperative alignment of $<10 \mathrm{PD}$.

However, multivariable analysis revealed that only the preoperative distant angle of deviation was significantly related to surgical outcome $(p=0.045)$. Patients with small preoperative distant angle of exodeviation showed more favorable outcome.

\section{Discussion}

In this study, $62.5 \%$ of patients with sensory exotropia had a successful outcome, with an average of $2.0 \pm 1.2$ years of follow-up. This result is comparable to those reported in other studies on sensory strabismus surgery, although the inclusion criteria and the length of follow-up vary widely among reports [4-6, 12].

In our study, we defined surgical success based on the distant angle of deviation. Fifty-eight of sixty-four patients had a larger or same distant angle of deviation compared to the near angle. The goal of surgery was initially orthotropia at far distance at postoperative day 1 as we beared known postoperative exodrift patterns in mind rather than initial overcorrection at near [13]. If surgical success had been defined based on the near angle of deviation then overcorrection would have been slightly higher compared with the distant angle of deviation.

In cases of large-angle exotropia, a three-muscle surgery is a rational option [14-16]. However, there has been no randomized controlled study comparing the results of recession-resection surgery on one eye and bilateral threeor four-muscle surgery in large-angle exotropia [17]. In patients with sensory exotropia, there is usually a strong preference for a monocular procedure to avoid surgery on 
Table 3 Deviation at postoperative day 1 in the successful and failure groups $\left(p=0.370^{\mathrm{a}}\right)$

\begin{tabular}{lllll}
\hline Alignment at postoperative day 1 & No. of patients & & \multirow{2}{*}{ Total } \\
\cline { 2 - 4 } & Overcorrection $(\%)$ & Success $(\%)$ & Recurrence $(\%)$ & \\
\hline 210 PD of esodeviation & $3(30.0)$ & $3(30.0)$ & $4(40.0)$ & 10 \\
0-10 PD of esodeviation/orthotropia & $1(2.0)$ & $34(68.0)$ & $15(30.0)$ & 50 \\
1-10 PD of exodeviation & 0 & $2(66.7)$ & $1(33.3)$ & 3 \\
Total & 4 & 39 & 20 & 63 \\
\hline
\end{tabular}

$P D$ prism diopters

${ }^{a}$ Comparison performed using linear-by-linear association the non-amblyopic eye [15]. Additionally, several studies have reported that good surgical outcome could be obtained with a two-muscle surgery in large-angle sensory exotropia $[5,15,17]$. Thus, we confined surgery to the amblyopic eye according to our surgical table.

Preoperative deviation has been proven to be a significant factor influencing a favorable outcome in patients with intermittent exotropia in several studies [18]. Moreover, there is widespread agreement that, because of postoperative exodrift, an initial overcorrection is desirable for a better long-term outcome in patients with intermittent exotropia [19, 20]. In our study in adult patients with sensory exotropia, regarding the factors affecting surgical outcome, we found that smaller preoperative distant and near angles of exodeviation are associated with success. A higher recurrence rate than overcorrection was also observed. However, initial postoperative overcorrection did not guarantee surgical success. Instead, esodrift during the first postoperative week was associated with success. This esodrift may be acting as a confounder for initial postoperative alignment to predict the final outcome. Ruttum reported that little predictability existed with respect to the direction of postoperative drift in intermittent exotropia; it was not clear why a minority of patients showed an esotropic drift, and this observation may be partly explained by the artifactual nature of the initial postoperative measurement [19]. Ruttum suggested that the contributions of pain, inflammation, blurred vision, and altered muscle dynamics may vary widely among patients [19]. Moreover, we could not clearly explain the presence of esodrift or instability of the initial postoperative alignment in sensory exotropia; however, short-term changes might be erroneous determination, dynamic changes of vergence tonus, chronic changes in muscle lengths [21].

Some studies have reported factors affecting the outcome after sensory strabismus surgery. Chung et al. reported that prolonged deviation after cataract surgery was a statistically significant factor contributing to final alignment, but they did not differentiate between the outcomes of congenital and traumatic cases [10]. Park
Table 4 Postoperative angle of deviation at each postoperative time point in each group

\begin{tabular}{|c|c|c|c|c|}
\hline & \multicolumn{4}{|c|}{ Angle of deviation in $\mathrm{PD}$, mean $\pm \mathrm{SD}$ (range) } \\
\hline & $\begin{array}{l}\geq 10 \text { PD of } \\
\text { esodeviation }\end{array}$ & $\begin{array}{l}<10 \mathrm{PD} \text { of } \\
\text { esodeviation/ } \\
\text { orthotropia }\end{array}$ & $\begin{array}{l}1-10 \text { PD of } \\
\text { exodeviation }\end{array}$ & $P$ value $^{\mathrm{a}}$ \\
\hline 1 day & $\begin{array}{l}-14.1 \pm 6.5 \\
(-30 \text { to }-10)\end{array}$ & $\begin{array}{l}-1.2 \pm 2.6 \\
(-9 \text { to } 0)\end{array}$ & $\begin{array}{l}4.7 \pm 3.1 \\
(2 \text { to } 8)\end{array}$ & $<0.001$ \\
\hline 1 week & $\begin{array}{l}-7.7 \pm 9.9 \\
(-30 \text { to } 0)\end{array}$ & $\begin{array}{l}-1.4 \pm 4.6 \\
(-14 \text { to } 10)\end{array}$ & $\begin{array}{l}-1.0 \pm 7.5 \\
(-9 \text { to } 6)\end{array}$ & 0.072 \\
\hline 3 months & $\begin{array}{l}-2.6 \pm 7.6 \\
(-15 \text { to } 5)\end{array}$ & $\begin{array}{l}1.9 \pm 7.9 \\
(-20 \text { to } 25)\end{array}$ & $\begin{array}{l}4.0 \pm 3.8 \\
(0 \text { to } 8)\end{array}$ & 0.307 \\
\hline 6 months & $\begin{array}{l}-1.6 \pm 11.5 \\
(-25 \text { to } 15)\end{array}$ & $\begin{array}{l}3.5 \pm 8.2 \\
(-12 \text { to } 30)\end{array}$ & $\begin{array}{l}6.0 \pm 7.9 \\
(0 \text { to } 15)\end{array}$ & 0.275 \\
\hline 1 year & $\begin{array}{l}-0.7 \pm 12.2 \\
(-25 \text { to } 12)\end{array}$ & $\begin{array}{l}4.7 \pm 9.0 \\
(-10 \text { to } 30)\end{array}$ & $\begin{array}{l}5.8 \pm 10.1 \\
(0 \text { to } 18)\end{array}$ & 0.599 \\
\hline $\begin{array}{l}\text { Final } \\
\text { follow-up }\end{array}$ & $\begin{array}{l}-0.4 \pm 12.7 \\
(-25 \text { to } 14)\end{array}$ & $\begin{array}{l}5.2 \pm 9.2 \\
(-10 \text { to } 30)\end{array}$ & $\begin{array}{l}6.7 \pm 11.5 \\
(0 \text { to } 20)\end{array}$ & 0.637 \\
\hline
\end{tabular}

The plus numbers represent exodeviation and the minus numbers represent esodeviation

$P D$ prism diopters, $S D$ standard deviation

${ }^{\mathrm{a} C}$ Comparison performed using Kruskal-Wallis test

et al. reported that adjustable surgery did not show a better result than non-adjustable sutures in sensory exotropia [9]. Gusek-Schneider et al. reported that surgical success in sensory exotropia was correlated with visual acuity in a total 19 patients [8]. Finally, Turan et al. reported that better visual acuity may predict better outcome in terms of long-term success in patients with sensory exotropia [4]. However, there were no significant factors associated with surgical outcome in our study. Although time of onset and the duration of vision impairment were not accurately evaluated, the causes of vision loss grouped based on the disease duration (congenital, anisometropic amblyopia, acquired) were not significantly associated with surgical success in our study [22].

In general, the surgical result in sensory exotropia in adults is less predictable than when visual acuity is normal in both eyes [7]. Long-term maintenance of ocular 
alignment in sensory strabismus is expected to be poor and recurrence high due to the low possibility of fusion gain or the very nature of sensory strabismus $[2,23,24]$. The surgeon is advised to inform patients of this possibility. It is known that eyes with long-standing sensory exotropia often develop mechanical abnormalities such as lateral rectus shortening or contracture with limitation [21]. Even though overcorrection or recurrence may eventually develop, surgery for sensory exotropia may produce satisfactory results for many patients. Some authors have reported that botulinum toxin is a good option to surgery for sensory strabismus; however, the results were variable [25].

To the best of our knowledge, although early postoperative alignment was not a significant factor affecting surgical outcome, this is the first study to evaluate this including other predictive factors in a sample of adult patients with sensory exotropia. However, this study is limited by its retrospective nature. Further, there could be a selection bias, because we only included patients followed up for more than 1 year, that is, patients with successful or poor results may not have returned to the clinic.

In conclusion, the long-term outcome of surgery for sensory exotropia was satisfactory, and patients with small preoperative distant angle of exodeviation showed more favorable outcome.

\section{Summary}

\section{What was known before}

- The factors reported to affect the surgical results after intermittent exotropia surgery vary widely, including age at the time of surgery, preoperative angle of deviation, refractive errors, type of surgery, and early postoperative ocular alignment.

- There is widespread agreement that, because of postoperative exodrift, an initial overcorrection is desirable for a better long-term outcome in patients with intermittent exotropia.

- However, little is known regarding the factors associated with surgical outcome in sensory exotropia.

\section{What this study adds}

- In adult patients with sensory exotropia, regarding the factors affecting surgical outcome, we found that smaller preoperative distant and near angles of exodeviation are associated with success.

- Regardless of the high rate of recurrence, initial postoperative large overcorrection did not guarantee surgical success.

\section{Compliance with ethical standards}

Conflict of interest The authors declare that they have no conflict of interest.

\section{References}

1. Hopker LM, Weakley DR. Surgical results after one-muscle recession for correction of horizontal sensory strabismus in children. J AAPOS. 2013;17:174-6.

2. Von Noorden GK, Campos EC. Binocular vision and ocular motility, 6th ed. St. Louis: CV Mosby. 2002:345-7.

3. Hunter DG. Benefits of strabismus surgery in patients with one blind eye. Arch Ophthalmol. 1995;113:404.

4. Erkan Turan K, Taylan Sekeroglu H, Sener EC, Sanac AS. Effect of visual acuity on the surgical outcomes of secondary sensory strabismus. Turk J Ophthalmol. 2015;45:254-8.

5. Merino P, Mateos C, Gomez De Liano P, Franco G, Nieva I, Barreto A. Horizontal sensory strabismus: characteristics and treatment results. Arch Soc Esp Oftalmol. 2011;86:358-62.

6. Oliveira BF, Bigolin S, Souza MB, Polati M. Sensorial strabismus: a study of 191 cases. Arq Bras Oftalmol. 2006;69:71-4.

7. Jung EH, Kim SJ, Yu YS. Factors associated with surgical success in adult patients with exotropia. J AAPOS. 2016;20:511-4.

8. Gusek-Schneider G, Boss A. Results following eye muscle surgery for secondary sensory strabismus. Strabismus. 2010;18:24-31.

9. Park YC, Chun BY, Kwon JY. Comparison of the stability of postoperative alignment in sensory exotropia: adjustable versus non-adjustable surgery. Korean J Ophthalmol. 2009;23:277-80.

10. Chung SE, Kyung SE, Oh SY. Prognostic factors for strabismus surgery after cataract surgery. J Cataract Refract Surg. 2007;33:297-300.

11. Nihalani BR, Whitman MC, Salgado CM, Loudon SE, Hunter DG. Short tag noose technique for optional and late suture adjustment in strabismus surgery. Arch Ophthalmol. 2009;127:1584-90.

12. Portes AV, Franco AM, Tavares MF, Souza-Dias CR, Goldchmit M. Surgical correction of permanent exotropia outcomes in amblyopic and non-amblyopic patients. Arq Bras Oftalmol. 2011;74:267-70.

13. Currie ZI, Shipman T, Burke JP. Surgical correction of large-angle exotropia in adults. Eye. 2003;17:334-9.

14. Lau FH, Fan DS, Yip WW, Yu CB, Lam DS. Surgical outcome of single-staged three horizontal muscles squint surgery for extralarge angle exotropia. Eye. 2010;24:1171-6.

15. Chang JH, Kim HD, Lee JB, Han SH. Supermaximal recession and resection in large-angle sensory exotropia. Korean J Ophthalmol. 2011;25:139-41.

16. Chen JH, Morrison DG, Donahue SP. Three and four horizontal muscle surgery for large angle exotropia. J Pediatr Ophthalmol Strabismus. 2015;52:305-10.

17. Thomas S, Guha S. Large-angle strabismus: can a single surgical procedure achieve a successful outcome? Strabismus. 2010;18:129-36.

18. Gezer A, Sezen F, Nasri N, Gozum N. Factors influencing the outcome of strabismus surgery in patients with exotropia. $\mathrm{J}$ AAPOS. 2004;8:56-60.

19. Ruttum MS. Initial versus subsequent postoperative motor alignment in intermittent exotropia. J AAPOS. 1997;1:88-91.

20. Scott WE, Keech R, Mash AJ. The postoperative results and stability of exodeviations. Arch Ophthalmol. 1981;99:1814-8. 
21. Guyton DL. The 10th Bielschowsky Lecture. Changes in strabismus over time: the roles of vergence tonus and muscle length adaptation. Binocul Vis Strabismus Q. 2006;21:81-92.

22. Havertape SA, Cruz OA, Chu FC. Sensory strabismus--eso or exo? J Pediatr Ophthalmol Strabismus. 2001;38:327-30. quiz 54-5
23. Kim MJ, Khwarg SI, Kim SJ, Chang BL. Results of re-operation on the deviated eye in patients with sensory heterotropia. Korean J Ophthalmol. 2008;22:32-6.

24. Edelman PM, Brown MH. The stability of surgical results in patients with deep amblyopia. Am Orthopt J. 1977;27:103-6.

25. Dawson EL, Sainani A, Lee JP. Does botulinum toxin have a role in the treatment of secondary strabismus?*. Strabismus. 2005;13:71-3. 